\title{
Cochlear implantation
}

\section{$A$ safe and cost effective treatment for profoundly deaf adults and children}

Last month saw the publication of a report by the Medical Research Council's Institute of Hearing Research on the evaluation of the national cochlear implant programme. ${ }^{1}$ Its authors, Summerfield and Marshall, report the results of a multicentre observational evaluation of the outcomes of implantation and set clear guidelines for clinicians who care for deaf people as well as for purchasers juggling the benefits and costs of this expensive treatment.

A cochlear implant is an electronic device that is inserted into the inner ear of a totally deaf person to introduce or restore the perception of sound. An external detachable component comprises a microphone, a small battery powered device for processing the signal, and an induction coil that transmits the refined signal through the skin to the implant. The notion that an electric current applied to the cochlea or to the auditory nerve might be perceived by the brain as sound is not new: Benjamin Franklin suggested the possibility 200 years ago. But the idea did not become a clinical reality until 1957, when Djourno and Eyries in Paris implanted a rudimentary single channel electrode into the ear of a patient who was having surgery to eradicate a cholesteatoma in his only hearing ear. ${ }^{2}$ By stimulating the electrode with an external current generator they were able to produce a perception of sound that the patient likened to crickets chirping. Cochlear implant technology evolved rapidly, and reliable commercially manufactured devices have been available for implantation since the 1980s. Otologists, especially those in Britain, initially viewed the technique with some scepticism ${ }^{34}$ : how could a relatively simple device replicate the complicated physiology of the human cochlea? But studies from North America, Australia, and Europe have now dispelled doubts about the effectiveness of cochlear implants in certain groups of totally deaf people. ${ }^{5}$

Who is likely to benefit from such surgery and to what extent? The Medical Research Council's study confirms that adults who become totally and bilaterally deafened after acquiring speech and language may be expected to do well. In most cases of acquired sensorineural deafness the cochlea is the main site of damage, with loss of the transducer mechanism of the organ of Corti but with an auditory nerve still capable of transmitting messages to the brain. Summerfield and Marshall found that when using the implant all of the totally deaf adults could identify common environmental sounds, $95 \%$ identified more words correctly when using the implant in conjunction with lip reading than they did when relying on lipreading alone, $50 \%$ could identify some words without lip reading, 35\% showed some understanding of questions posed over the telephone, $70 \%$ showed improvements in the quality and intelligibility of their own speech, and $50 \%$ of those with tinnitus reported its partial or complete resolution. Of course, hearing tests are not everything. More than $90 \%$ of adults with the implants reported an overall improvement in their quality of life and reduced dependence on others. In a cost utility analysis cochlear implantation compared well with other treatments currently available in Britain.

The other group of people who derive considerable benefit from implants are young children, including those who are born deaf or who become deaf before they learn spoken language. If such children can be given implants before their auditory pathways lose their plasticity they may be expected to acquire intelligible speech and to be educated in mainstream schools. The "ideal" age for such intervention is becoming progressively younger and will ultimately depend on the earliest age at which a child can reliably be diagnosed as being totally deaf. Two years of age seems to be the current ideal, but there is every reason to suppose that this will be lowered with time. The sooner that sound can be introduced into the developing auditory system the better will be the linguistic result. ${ }^{6}$ After the age of 7 years the plasticity of the auditory pathways lessens rapidly. Congenitally deaf children who are given implants in their teens or later will do badly. ${ }^{\text {? }}$ A totally deaf child therefore has a short time within which to benefit from a cochlear implant, and the urgency of the situation must be recognised by providers and purchasers; even one year's delay may have serious effects on the child's acquisition of language.

The adult subjects in Summerfield and Marshall's study had, in audiometric terms, the least favourable profile, because they obtained no benefit from conventional acoustic hearing aids. There is reason to expect an equally good outcome in so called "marginal hearing aid users" or people with severe rather than total hearing impairment. Widening the selection criteria would of course have financial implications (each device plus surgery and rehabilitation costs between $£ 25000$ and $£ 30000$ ), but it seems possible that the benefits will outweigh the additional expense.

Any review of a new surgical technique would be incomplete without considering the risks of the operation. Major complications such as infection or malpositioning of the implant requiring surgical revision occur in under $5 \%$ of cases. ${ }^{8}$ The risks to the facial nerve are very low and do not exceed those of any major ear operation.

Cochlear implantation is perhaps the most exciting development in otology this century. The benefits are immense. The report by Summerfield and Marshall confirms that, in the words of the late Graham Fraser, the founder of the British Cochlear Implant Group, "Cochlear implants work."

RICHARD RAMSDEN

Professor of otolaryngology

Manchester Royal Infirmary,

Manchester M13 9WL

JOHN GRAHAM

Ferens Institute, Consultant otolaryngologist

University College London,

London W1P 5FD

1 Summerfield AQ Marshall DH. Cochlear implantation in the UK 1990-1994. Report by the MRC Instizute of Hearing Research on the evaluation of the national cochlear implant programme. London HMSO, 1995.

2 Djourno A, Eyries C. Prothese auditive par excitation electrique a distance du nerf sensoriel a l'aide d'un bobinage inclus a demeure. Presse Med 1957;36:14-7.

Brimacombe JA, Arndt PL, Staller SJ, Beiter AL. Multichannel cochlear implantation in adults with severe-to-profound sensorineural hearing loss. In: Hochmair-Desoyer IJ, Hochmair ES, eds. Advances in cochlear implants. Vienna: Manz, 1994:387-92.

4 Haggard M. Implants in perspective. In: Cooper HW, ed. Cochlear implants: a practical guide. London: Whurr, 1991:1-8.

5 Ganz BJ, Tyler RS, Woodworth GG, Tye-Murray N, Fryauf-Bertschy H. Results of multichanne cochlear implants in congenital and acquired prelingual deafness in children: five year follow-up. Am F Otol 1994;15:2.

6 Waltzman SB, Cohen NL, Gomolin RH, Shapiro WH, Ozdamar SR, Hoffman RA. Long term results of early cochlear implantation in congenitally and prelingually deafened children. $\mathrm{Am} \mathfrak{f}$ Otol 1994;15:2.

Chute PM. Cochlear implants in adolescents. In: Fraysse B, Geguine O, eds. Cochlear implants: new perspectives. Basel: Karger, 1993:210-5.

Babighian G. Problems in cochlear implant surgery. In: Fraysse B, Deguine O, eds. Cochlear implants: new perspectives. Basel: Karger, 1993:65-9. 